\title{
Three Colon Adenocarcinomas Arising in a Patient with Serrated Polyposis Syndrome: Case Report and Review of the Literature
}

\author{
Emmanouil Pyleris loannis S. Koutsounas Panagiotis Karantanos \\ Department of Gastroenterology and Endoscopy Unit, Sismanogleion General Hospital, Marousi, Greece
}

\section{Keywords}

Serrated polyposis syndrome - Hyperplastic polyp . Serrated adenoma $\cdot$ Serrated neoplasia

\section{Summary}

Background: Serrated polyposis syndrome (SPS) is a rare entity mainly concerning the 6th decade of life and which is characterized by the presence of multiple large hyperplastic polyps, sessile serrated adenomas, and adenomas within the colon. Case Report: We describe the case of a SPS patient with 3 synchronous adenocarcinomas. The morphologic features of serrated colorectal lesions, their characteristic molecular alterations, and their role in colorectal cancer development are discussed herein. Conclusion: Our findings suggest that SPS is a rare condition with an increased risk for colon cancer. Patients suffering from SPS should have regular colonoscopic surveillance, and perhaps those with numerous dysplastic hyperplastic polyps should be treated with colectomy.

\section{Introduction}

Colorectal cancer (CRC) is the second most frequent malignancy and the third most common cause of cancer-related death in the developed world. Genetic or environmental factors are implicated in CRC development. CRC is considered as one of the most preventable cancers because it usually develops from lesions which can be easily detected with colonos-

\section{Schlüsselwörter}

Serratiertes Polyposis-Syndrom - Hyperplastischer Polyp - Serratierte Adenome · Serratierte Neoplasien

\section{Zusammenfassung}

Hintergrund: Das serratierte Polyposis-Syndrom (SPS) ist eine seltene Erkrankung, die vor allem die sechste Lebensdekade betrifft und die durch die Anwesenheit von mehreren großen hyperplastischen Polypen, sessilen serratierten Adenomen sowie Adenomen im Kolon gekennzeichnet wird. Fallbericht: Wir beschreiben im Folgenden den Fall eines SPS-Patienten mit 3 synchronen Adenokarzinomen. Die morphologischen Merkmale von serratierten kolorektalen Läsionen, ihre charakteristischen molekularen Veränderungen und ihre Rolle in der Entstehung von kolorektalen Karzinomen werden zudem diskutiert. Schlussfolgerung: Unsere Ergebnisse legen nahe, dass das SPS eine seltene Erkrankung mit einem erhöhten Risiko für Darmkrebs darstellt. Bei Patienten mit SPS sollten regelmäßige Koloskopieüberwachungen durchgeführt werden, und eventuell sollten diejenigen Patienten mit zahlreichen dysplastischen hyperplastischen Polypen einer Kolektomie unterzogen werden.

copy. Independently of the aetiologic factor, chromosomal instability (CIN), microsatellite instability (MSI), and CpG island methylator phenotype (CIMP) are the main alterations involved in CRC [1].

Until recently, it has been thought that most CRCs arise from conventional adenomas via the traditional tumor suppressor pathway initiated with a mutation of the $A P C$ gene, but it has been found that this pathway accounts for only ap-

\begin{tabular}{ll}
\hline KARGER & @ 2014 S. Karger GmbH, Freiburg \\
Fax +49 761 45207 14 $526664 / 14 / 0302-0136 \$ 39.50 / 0$ \\
$\begin{array}{l}\text { Information@Karger.com } \\
\text { www.karger.com }\end{array}$ & $\begin{array}{l}\text { Accessible online at: } \\
\text { www.karger.com/vim }\end{array}$
\end{tabular}

\section{KARGER}

www.karger.com 
proximately $70-80 \%$ of CRC cases. The majority of the remaining CRC cases follow an alternative pathway leading to $\mathrm{CpG}$ island methylator carcinoma with $B R A F$ mutation as well as with or without MSI. This pathway is called the serrated pathway of colorectal carcinogenesis [2-4]. The mechanism of carcinomas arising from this alternative pathway seems to begin with an activating mutation of the $B R A F$ oncogene. This $B R A F$ mutation provokes the development of serrated lesions that are mainly microvesicular hyperplastic polyps or sessile serrated adenomas (SSAs). These lesions are prone to methylation of $\mathrm{CpG}$ islands in the promoter regions of genes, resulting in their epigenetic silencing. The best characterized gene silenced by this mechanism is MLH1 [5].

A patient is diagnosed with serrated polyposis syndrome (SPS) if at least one of the following criteria is met: i) At least 5 histologically diagnosed serrated polyps proximal to the sigmoid colon, of which 2 are greater than $10 \mathrm{~mm}$; ii) any number of serrated polyps proximal to the sigmoid colon in an individual who has a first-degree relative with SPS; iii) more than 20 serrated polyps of any size distributed throughout the colon [6].

SPS is a rare condition first reported 30 years ago. Although it was referred to as a disease with low malignant potential, there has been a number of reports in the English literature on individuals with SPS who developed synchronous or metachronous adenocarcinomas, amounting to $51.1 \%$ of the reported cases of SPS [7]. Boparai et al. [8] have recently described an increased risk of CRC (relative risk $(\mathrm{RR})=5.4$ ) and SPS $(\mathrm{RR}=39)$ in first-degree relatives of patients diagnosed with SPS compared to the general population. SPS affects both sexes equally. The mean age of the patients at the time of diagnosis is 57 years. The prevalence of SPS in autopsies ranges among $5-11 \%$ in adults, increasing with age. Hyperplastic polyps (HPs) are the commonest polyps of the sigmoid colon and rectum. Smoking, being overweight, and the use of some drugs have been postulated as potential risk factors for HPs. HPs can be solitary or multiple, and they are often found incidentally either during endoscopy or in surgical specimens. SPS is characterized by the presence of multiple HPs spread throughout the colon. Published case series report that between 10 and $50 \%$ of patients meeting SPS criteria have a family history of CRC $[5,9,10]$. The lifetime risk of CRC is estimated to be about $50 \%$ [11]. Besides HPs, SSAs and conventional adenomas are common findings in these patients [12].

Opposed to serrated adenomas (SAs) which tend to be associated with dysplasia and furthermore with CRC, SSAs are characterized by an abnormal proliferation without epithelial dysplasia [13]. HPs have been divided into two main histological subtypes: microvesicular serrated polyps (MVSPs) and goblet cell serrated polyps (GCSPs), which are predominantly found in the distal colon [4]. MVSPs seem to be the precursor lesion of SSA, especially when located in the right colon. SSAs are larger than HPs and more frequently located in the right colon. Histologically, SSAs are distinguished from typical HPs by the presence of inverted T- or L-shaped crypt bases that reflect disordered proliferation.

HPs appear pale, glistening, very similar to the surrounding mucosa, and are usually covered by mucus. The vascular network is weak, in contrast to that of hypervascular adenomas. In addition, serrated polyps, mainly SSAs, are typically sessile or flat, making their detection even more difficult [14]. It is unclear whether chromoendoscopy improves the detection of small and flat lesions, while it is a time-consuming technique [15-17]. Compared to standard colonoscopy, high resolution colonoscopy with chromoendoscopy seems to improve the detection of purely flat adenomas and HPs [18]. Additionally, it was shown that narrow band imaging (NBI) has a significantly lower polyp miss rate than conventional or even high resolution endoscopy (HRE), especially for the detection of serrated polyps [9].

In this report, we add another case to the list of SPS patients who developed colon cancer and, to the best of our knowledge, one of the few reports regarding SPS individuals presenting with 3 synchronous adenocarcinomas.

\section{Case Report}

A 58-year-old male with a family history of adenocarcinoma of the colon visited the emergency department complaining of abdominal pain, bloody stools, and watery diarrheas for the last month.

The laboratory tests showed anemia. Colonoscopy was performed, and numerous sessile polyps were revealed throughout the colon, which in serial biopsies were diagnosed to be HPs. Only one lesion had the histology of an SA with high-grade dysplasia. Upper gastrointestinal endoscopy was unremarkable. The patient fulfilled the World Health Organization criteria of SPS. Due to the number of the polyps, he underwent a total colectomy.

Throughout the large bowel, measured up to approximately $150 \mathrm{~cm}$, 102 sessile and 3 pedunculated polyps were found. The pedunculated ones were seated in the sigmoid colon and measured up to 1, 1.5, and 2 $\mathrm{cm}$. Within their stalk, whitish, solid foci were detected. Overall, 52 polyps had the classical morphology of the HPs, 49 had a serrated morphology with dysplastic changes, and 1 was a mixed adenoma and metaplastic polyp. The pedunculated polyps were well differentiated mucous-producing adenocarcinomas (T1, N0).

The patient remained under surveillance every 6 months for the first year after the operation and annually thereafter. 6 new metaplastic polyps and 2 adenomas with high-grade dysplasia have been removed from the pouch during the last 2 years.

\section{Discussion}

SA was originally introduced in the 1990s as a distinct neoplastic lesion that shared mixed features of HPs and adenoma, such as the serrated configuration of HP, but also clear evidence of at least low-grade surface epithelial dysplasia of adenoma. SAs are difficult to diagnose and are often misclassified. In 2003, Torlakovic et al. [5], in a review of a series of SPS patients, 
described polyps that shared some features of SA but maintained a sessile configuration. Thus, the term SSA was introduced to distinguish these lesions from the pedunculated counterpart which was named transitional serrated adenoma (TSA).

Polyps of our SPS patient were typical HPs with prominent atypical cytological features in almost half of them. Histology revealed that $50 \%$ of the polyps $(52 / 105)$ had the classical morphology of the HPs, while almost half of the polyps (49/105) had a serrated morphology with dysplastic changes and fulfilled the criteria of SAs. Only 1 was a mixed adenoma/ metaplastic polyp. In the present case, adenocarcinomas have arisen de novo without evidence of adenomatous or serrated epithelium in their vicinity.

It has been suggested that the atypia seen in sporadic SAs reflects neoplastic progression in an otherwise hyperplastic or metaplastic lesion and that such lesions may represent an alternative pathway to colorectal carcinogenesis named serrated pathway $[13,19,20]$. Over the past years, increasing data for biological and genetic similarities between them supported this hypothesis. Molecular studies show a higher number of $B R A F$ mutations, $K$-ras, and CIMP in serrated polyps of SPS patients compared with sporadic SAs [9, 21].

The finding of multiple SAs in the setting of SPS has led to speculations that individuals with this condition also show a significant increase in cancer risk that is analogous to the increased risk seen in adenomatous polyposis. However, ascertainment bias will certainly favor the identification of SPS in the presence of synchronous carcinoma.

A long debate has been started regarding the endoscopic surveillance follow-up. SPS was referred to as a disease with low malignant potential; however, in the recent literature a number of reports have been made on individuals with SPS who developed synchronous or metachronous adenocarcino- mas, amounting to $51.1 \%$ of the reported cases of SPS [7]. A multicenter cohort study showed that CRC among SPS was detected in a much higher percentage in comparison with the general population ( 35 vs. $6 \%$ ). Although there are no uniform protocols and guidelines, it is acceptable that the surveillance intervals range from 1 to 3 years [22]. Regarding SPS management, it is acceptable that diminutive HPs of the left colon and rectum can be managed conservatively only by documenting that they are HPs with typical histology. Isolated serrated polyps of the right colon should be removed completely and followed up in the same fashion as adenomas. Finally, regarding SSAs, follow-up colonoscopy should be conducted at an interval no less frequent than that for adenomas of corresponding size, number, and degree of dysplasia [8].

Another reason that indicates why SPS patients should receive regular surveillance is the fact that, while colon cancer in most SPS patients was diagnosed at the time of SPS diagnosis (synchronously), there are a few patients with cancer diagnosed only after colectomy, as in our case. Our patient was treated with total colectomy because the polyps were too numerous to allow adequate colonoscopic surveillance, and 3 adenocarcinomas infiltrating the submucosa were diagnosed on colectomy specimen.

In conclusion, our findings propose the view that SPS is a rare condition with an increased risk for colon cancer. Patients suffering from SPS should have regular colonoscopic surveillance, and perhaps those with numerous dysplastic HPs should be treated with colectomy.

\section{Disclosure Statement}

No conflict of interest.

\section{References}

1 Wong JJ, Hawkins NJ, Ward RL: Colorectal cancer: a model for epigenetic tumorigenesis. Gut 2007;56:140-148.

2 Fearon ER, Vogelstein B: A genetic model for colorectal tumorigenesis. Cell 1990;61:759-767.

$\checkmark 3$ Jass JR: Classification of colorectal cancer based on correlation of clinical, morphological and molecular features. Histopathology 2007;50:113-130.

4 Leggett B, Whitehall V: Role of the serrated pathway in colorectal cancer pathogenesis. Gastroenterology 2010;138:2088-2100.

5 Torlakovic E, Skovlund E, Snover DC, Torlakovic G, Nesland JM: Morphologic reappraisal of serrated colorectal polyps. Am J Surg Pathol 2003;27: $65-81$.

6 Snover DC, Ahnen DJ, Burt RW, Odze RD: Serrated polyps of the colon and rectum and serrated ('hyperplastic') polyposis; in Bosman ST, Carneiro F, Hruban RH, Theise ND (eds): WHO Classification of Tumours of the Digestive System, ed 4. Lyon, International Agency for Research on Cancer, 2010, pp 160-165.
7 Abeyasundara H, Hampshire P: Hyperplastic polyposis associated with synchronous adenocarcinomas of the transverse colon. ANZ J Surg 2001;71: 686-687.

8 Lynch PM: Hyperplastic polyposis: semantics, biology, and endoscopy. Gut 2010;59:1019-1021.

9 Boparai KS, van den Broek FJ, van Eeden S, Fockens P, Dekker E: Increased polyp detection using narrow band imaging compared with high resolution endoscopy in patients with hyperplastic polyposis syndrome. Endoscopy 2011;43:676-682.

10 Jass JR, Young J, Leggett BA: Hyperplastic polyps and DNA microsatellite unstable cancers of the colorectum. Histopathology 2000;37:295-301.

11 Jarrar AM, Church JM, Fay S, Kalady MF: Is the phenotype mixed or mistaken? Hereditary nonpolyposis colorectal cancer and hyperplastic polyposis syndrome. Dis Colon Rectum 2009;52:1949-1955.

12 Rubio CA, Stemme S, Jaramillo E, Lindblom A: Hyperplastic polyposis coli syndrome and colorectal carcinoma. Endoscopy 2006;38:266-270.

13 Orlowska J: Hyperplastic polyposis syndrome and the risk of colorectal cancer. Gut 2012;61:470-471; author reply 471-472.
14 East JE, Saunders BP, Jass JR: Sporadic and syndromic hyperplastic polyps and serrated adenomas of the colon: classification, molecular genetics, natural history, and clinical management. Gastroenterol Clin North Am 2008;37:25-46.

15 Lapalus MG, Helbert T, Napoleon B, Rey JF, Houcke P, Ponchon T: Does chromoendoscopy with structure enhancement improve the colonoscopic adenoma detection rate? Endoscopy 2006; 38:444-448.

16 Hashimoto K, Higaki S, Nishiahi M, Fujiwara K, Gondo T, Sakaida I: Does chromoendoscopy improve the colonoscopic adenoma detection rate? Hepatogastroenterology 2010;57:1399-1404.

17 Aminalai A, Rosch T, Aschenbeck J, Mayr M, Drossel R, Schroder A, Scheel M, Treytnar D, Gauger U, Stange G, Simon F, Adler A: Live image processing does not increase adenoma detection rate during colonoscopy: a randomized comparison between FICE and conventional imaging (Berlin Colonoscopy Project 5, BECOP-5). Am J Gastroenterol 2010;105:2383-2388. 
18 Le Rhun M, Coron E, Parlier D, Nguyen JM, Ca nard JM, Alamdari A, Sautereau D, Chaussade S, Galmiche JP: High resolution colonoscopy with chromoscopy versus standard colonoscopy for the detection of colonic neoplasia: a randomized study. Clin Gastroenterol Hepatol 2006;4:349-354.

19 Muzaffar M, Irlam J, Mohamed I: Association of hyperplastic polyposis syndrome, colorectal cancer and meningioma. Hematol Oncol Stem Cell Ther 2011;4:136-137.
20 Kalady MF, Jarrar A, Leach B, LaGuardia L, O'Malley M, Eng C, Church JM: Defining phenotypes and cancer risk in hyperplastic polyposis syndrome. Dis Colon Rectum 2011:54:164-170.

21 Boparai KS, Dekker E, Polak MM, Musler AR, van Eeden S, van Noesel CJ: A serrated colorectal cancer pathway predominates over the classic WNT pathway in patients with hyperplastic polyposis syndrome. Am J Pathol 2011;178:2700-2707.
2 Boparai KS, Mathus-Vliegen EM, Koornstra JJ, Nagengast FM, van Leerdam M, van Noesel CJ, Houben M, Cats A, van Hest LP, Fockens P, Dekker E: Increased colorectal cancer risk during follow-up in patients with hyperplastic polyposis syndrome: a multicentre cohort study. Gut 2010;59: 1094-1100. 